Original Article

\title{
Knowledge regarding Leucorrhoea among women residing in selected urban community of Ludhiana City
}

\section{Mamta Choudhary}

Nursing Tutor, College of Nursing, AllMSJ odhpur, Rajasthan

*Corresponding Author: Mamta Choudhary, Nursing Tutor, College of Nursing, AllM SJ odhpur, Rajasthan - 342005.

M obile : +9198032 27705 E-mail : mamta24.c@gmail.com

Received

: 30-06-2015

Review Completed : 13-05-2016

Accepted

:14-05-2016

Keywords : Leucorrhea, vaginal discharge.

\begin{tabular}{|c|}
\hline Access this article online \\
\hline Quick Response Code \\
\hline
\end{tabular}

\begin{abstract}
:
Background: Reproductive tract infections form one of the major burdens of disease in developing countries. Most of the women suffer from leucorrhoea and do not present themselves for seeking medical treatment in early stage as the women has poor understanding regarding leucorrhoea.
\end{abstract}

Objectives: To assess the knowledge of females regarding leucorrhoea.

Study Design : Cross- sectional study.

Materials and Methods: The study involved collection of information regarding knowledge of females about leucorrhoeausingmultiple-choice questionnaire. Two hundred and fifty females residing in M odel Town, Ludhiana were recruited in the study by using convenient sampling.

Results: The result revealed that only $20 \%$ of subjects had good level of knowledge, and $80 \%$ subject had poor level of knowledge regarding leucorrhoea. The mean knowledge score regarding leucorrhoea among subjects was 19 with a standard deviation of 3.94. The highest mean knowledge score of $19.5 \pm 4.69$ was in the age group of $>35$ years.

\section{Introduction}

Reproductive tract infections form one of the major burdens of disease in developing countries, and include infections caused due to any (or combination) of the three factors: iatrogenic, endogenous, and sexually transmitted. While there are many symptoms that define the disease, the most commonly reported among the women is that of abnormal vaginal discharge or Leucorrhoea. Various community based studies in developing countries have revealed that this morbidity and general ill health has been endured silently by women, due to various factors like gender inequalities, cultural restrictions, lack of women autonomy, poor awareness, lack of proper infrastructure, and lack of focussed counselling services. ${ }^{1,2,3}$

The term leucorrhoea denotes a thick, whitish vaginal discharge. It is a natural defence mechanism that the vagina uses to maintain its chemical balance as well as preserve the flexibility of vaginal tissue. Normally, the secretion is just enough to lubricate vagina. When the vaginal secretion increases more than normal it causes excoriation $\&$ soreness of vulva. If white vaginal discharge is associated with foul smell, it makes embarrassing to the women to get into social gatherings and even in personal affairs. The affected woman needs treatment and counselling regarding the problem. If it is not treated in the initial stages, it may become chronic. ${ }^{4}$

Several studies show that women often suffer from reproductive morbidities for a long time because of their 'culture of silence' and they believe that it's not a condition for which they should seek medical help. Hence it is the responsibility of the health care provider to create awareness regarding leucorrhoea which helps in early identification of problem in the initial stage.Keeping the above facts in view investigator has decided to assess knowledge regarding leucorrhoea among womenresiding in selected urban community of Ludhiana city.

\section{M aterial and Methods}

The cross sectional study was conducted in the Model town 
area of Ludhiana. Eligibility criteria for inclusion included female residents of Model Town area in the age group of 18-45 years and who can understand or read Punjabi language. 250 females were recruited in the study by using convenient sampling. Information was collected by administering a pretested questionnaire to the subjects. The Questionnaire related to Socio demographic variables and knowledge items related to leucorrhoea was developed by reviewing literature. After establishing content validity of the instrument, it was translated to vernacular language. Permission to conduct study was taken from the concerned authority.

After explaining purpose of the study and taking verbal consent from the participants, the subjects were asked to fill the questionnaire in the presence of nursing students. They were not permitted to communicate with each other.

The Socio-demographic variables of the study included age, education, occupation, and personal experience of leucorrhoea of the subjects. Questionnaire related to knowledge items regarding leucorrhoea consisted of 30 open ended multiple choice questions. Data were coded, validated and analyzed using SPSS (version 18). Each of the 30 knowledge questions were rated using a score of one for correct answer and zero for an incorrect answer, with a total score ranging from $0-30$. Subjects having a score above $75^{\text {th }}$ percentile i.e. with score of 23 and above were regarded as having good level of knowledge.

\section{Results}

Maximum of the subjects were of the age group of $>35$ years with mean age of 35.47 years and standard deviation of 12.53 . Majority $85 \%$ subjects were graduates or more, however only $15 \%$ were educated up to senior secondary or less. Maximum $60 \%$ of the subjects were housewives and $40 \%$ were working. The data was collected from $53.6 \%$ subjects with personal experience of leucorrhoea, however $46.4 \%$ had never experienced it. The result revealed that only $20 \%$ of subjects had good level of knowledge, and $80 \%$ subject had poor level of knowledge regarding leucorrhoea. The mean knowledge score regarding leucorrhoea among subjects was 19 with a standard deviation of 3.94. The highest mean knowledge score of $19.5 \pm 4.69$ was in the age group of $>35$ years. Subjects with educational qualification of graduation had more mean knowledge score of 22.00 as compared to those studied up to senior secondary educational level.The working women had more mean knowledge score of 19.6 \pm 4 . 44 than subjects who were housewives. The relation of knowledge regarding leucorrhoea with selected sociodemographic variables such as age, education, occupation was non-significant at $p<0.05$. (Table 1). However the subjects who had previous experience of leucorrhoea had significantly more knowledge score of $20.1+4.26$ as compared to those who had no previous experience of leucorrhoea.

Table 1 : Comparison of mean value of CAD prevention knowledge scoreamong subjects

$\mathrm{N}=\mathbf{2 5 0}$

\begin{tabular}{|c|c|c|c|c|}
\hline Variable & $\mathbf{n}$ & $\begin{array}{l}\text { Mean } \\
\text { Score }\end{array}$ & $\begin{array}{c}\text { Standard } \\
\text { Deviation }( \pm)\end{array}$ & P value \\
\hline \multicolumn{5}{|l|}{$\overline{\text { Age }}$} \\
\hline$<35$ years & 109 & 18.97 & 5.87 & 0.43 \\
\hline$>35$ years & 141 & 19.50 & 4.69 & \\
\hline \multicolumn{5}{|l|}{ Education } \\
\hline$\geq 10+2$ & 38 & 22.60 & 3.85 & 0.37 \\
\hline Graduate & 212 & 22.00 & 3.77 & \\
\hline \multicolumn{5}{|l|}{ Occupation } \\
\hline Housewives & 150 & 19.0 & 3.37 & 0.22 \\
\hline Working & 100 & 19.6 & 4.44 & \\
\hline \multicolumn{5}{|c|}{ Previous Experience of Leucorrhoea } \\
\hline Yes & 134 & 20.1 & 4.26 & $0.001 *$ \\
\hline No & 116 & 18.2 & 3.28 & \\
\hline
\end{tabular}

*Significant at $p<0.05$

\section{Discussion}

Findings of the study reveal that majority study subjects had poor knowledge regarding leucorrhoea. The findings of the study are consistent with various previous studies ${ }^{5,6}$ ${ }^{7}$. The findings of the study call the health workers to take steps ahead to enhance knowledge of general population regarding this morbidity. In this study the knowledge is compared with the variables such as age, education, occupation and personal experience of leucorrhoea of the subjects. The study found a non-significantassociation of knowledge regarding leucorrhoea with socio-demographic variables such as age, education and occupation. However the subjects who had previous experience of leucorrhoea had significantly more knowledge score of $20.1 \pm 4$.26as 
compared to those who had no previous experience of leucorrhoea.The study has a limitation that the sample was drawn from a local urbanarea, the characteristics of people

\section{References}

1. Joshi A, Dhapola M, Pelto P. Gynaecological Problems: Perceptions and Treatment-seeking Behaviours of Rural Gujarati Women: Reproductive Health in India New Evidence: Rawat Publications; 2008. pp. 133-58.

2. Bhatia, Bhatia JC, Cleland J, Bhagavan L, Rao NS. Levels and determinants of gynecological morbidity in a district of south India. Stud FamPlann. 1997; 28:95-103.

3. GittlesohnJ, Holmes KK, Pilot P, et al. Listening to Women Talk about Their Health: Issues and Evidence from India. New Delhi: Har-Anand Publications; 1994. pp. 21-36.

4. Balmurugan SS and Bendigeri ND. Community- based study of reproductive tract infections among women of the reproductive age group in the urban health training centre area in Hubli, Karnataka. Indian] Community M ed [serial online] 2012 [cited 2012 Dec 3];37:348. Available from: http:// www.ijcm.org.in/2012/371/1/34/94020.

5. Mazhar S. B, Agha M.A. Shaikh M. A. Knowledge and misconceptions about sexually transmitted infections in married women - perspective from Islamabad. J ournal of the Pakistan medical association. 2006; 56. Available from: http://www.jpma.org.pk/2800.pdf residing in the area may differ from that of the city population. Furthermore, as it was a quantitative study, the data collected were relatively brief and concise.

6. Kabibu A Rabiu, Adeniyu A Adewunmi, Fatimat M Akinlusi, Oluwarotimi I Akinola. Female reproductive tract infections: understanding and care seeking behaviour among women of reproductive age group in Lagos, Nigeria. BMC Women's Health.2010,10.1186/1472-6874-10-8. Available from http://www.biomedcentral.com/1472-6874-10-8

7. Jaspreetkaur and AK Kapoor. Perception and knowledge regarding leucorrhea in a slum dwelling south asian community. J ournal of family and reproductive health. Available from: http://www.pubfacts.com/ detail/24971133/Perceptions-and-Knowledge-about-Leukorrhea-ina-Slum-Dwelling-South-Asian-Community

8. Beryl West, Bernice Nayak. Why do women complain of vaginal discharge:Apopulation survey of infectious and psycholosocial risk factors in a South Asian community, Int. J. Epidemiology 2005;34(4):853-862.

9. Abraham E. rakoff, P.Brookebland,Leukorrhea:clinical and therapeutic aspect, J Am M ed Assoc (1940); 115(12): 1013-1018.

10. Eschenbach, Vaginal infection, Clinical Obstetrics and Gynecology, 26: 186-202. Adv. In Nat. Appl. Sci., 2010; 4(2):148-152. 